\title{
The influence of stereotypes about old age on the perception of elderly employees' labor activity
}

\author{
Marina Makienko ${ }^{1 \mathrm{a}}$, Anna Panamareva ${ }^{1}$ \\ ${ }^{1}$ Tomsk Polytechnic University, 634050 Lenin Avenue, 30, Tomsk, Russia
}

\begin{abstract}
In this article the problem of increasing retirement age in terms of age discrimination and creating conditions encouraging elderly people to continue to work is discussed. This paper presents a study of stereotypes that affect students of management specialties in Russian institutions of higher education between the ages of 20 to 25 years old. The stereotype is investigated in the context of emotionally colored image of reality simplifying the process of perceiving it. The correlation between the students' existing stereotypes about elderly people and their perception of older employees has been conducted. As a result, 5 stereotypes that exist in young people have been defined. An analysis of the words chosen by students to describe the elderly shows little diversity in young people's perception of them. Lexical analysis shows that in the Russian language there are practically no concepts which allow creating a positive image of the elderly. The influence of the stereotypes on the perception of elderly people in terms of employment shows that older specialists are perceived as people with experience and knowledge but these experience and knowledge are irrelevant to the present.
\end{abstract}

\section{Introduction}

The research topicality is determined by the following demographic trends in the modern world: a decline of birth and infant mortality rates, an increase in the total population aged over 65 years [1], which entails significant demographic changes and, as a result, keeps current political, economic and social transformations. The interpretation of them is carried out at a theoretical level in scientific research, at the national level - as transformation of public policy, at the international level - in the form of various forecasts, recommendations to governments, conventions. Here are some examples. A work by renowned management theorist Peter Ferdinand Drucker, «Management Challenges for the 21st Century», has recently been published, where an attempt is made to present current trends that will have a significant impact on the principles of management in the XXI century. [2] Drucker highlights the following as the main trends: changes in the structure of demand in the market of goods and services due to the decline of the birth rate, expressed as the increase in demand for products for children and the elderly; changes in the structure of the working population - increase in the number of working elderly people and, as a result, a change of labor relations; transformation of financial markets because of the increase in the share of long-term investments in the form of a pension; rapid growth in

\footnotetext{
$\bar{a}$ Corresponding author: mma1252@gmail.com
}

some areas of industry (pharmaceutical, information) and some services (educational, financial).

At the state level, various instruments to reduce the effects of population aging are adopted. For example, currently in Russia the "National Strategy of Action for Older Persons 2015" is under discussion. The main directions of the Strategy are the following: increase in the real level of pensions of citizens, employment of senior citizens, the development of mechanisms of social support for the elderly, improving the health of middle and older age groups and the extension of their active longevity, improving health and social services for the elderly, the formation of a positive image of elderly citizens, participation in various spheres of life, the protection of the rights of the elderly [3]. At the international level, we can mark the "Report on the Global Financial Stability made in April, 2012, by the International Monetary Fund, which includes the chapter "The financial implications of longevity risk". [4] The following problems are formulated: existing pension schemes and social security arrangements are difficult for the governments of various states; pension plans with defined benefit will be a problem for corporate employers, the lack of guaranteed pension benefits is already a problem for people who do not work (for example, women who were housewives) or officially unemployed citizens.

Statistical data confirm the need for Russia's ongoing understanding of demographic changes. In Russia, 
according to the State Statistics Committee on January 23,2015 , the population is 146270033 ; on January 1, 2014 the population is 143666931 people [5]. The population of working age is $60.1 \%$. The average woman age is 41.62 years old; the average man age is 36,55 years old. A demographic load indicator is 664 people out of 1000. On January 1, 2014, 33.1 million people in Russia are the people of retirement age, which means that every fifth person in the state is a pensioner. [5] In Russia, the retirement age is 55 for women, 60 for men. According to the statistical practice of the United Nations, a state is considered to be aging if the proportion of people aged 65 years and older is higher than $7 \%$. In Russia, $12.9 \%$ people are of the 65 year age and older. Despite some positive trends (the birth rate increased in 2013 to 1,707 children per 1 woman, compared to 2010 - 1,567 people), the number of deaths in January 2014 is by $9.6 \%$ more than the number of births. Taking into account that the projected life expectancy for people born in 2014 at a low version of the forecast will be 68.8 years, while the high version 71.8 [5] (for people born in $1961-68,75$ years) and then there is a tendency to increase life expectancy, the organization of life of elderly people is of high current importance for Russia.

\section{Materials and methods}

According to the results of the international symposium on aging in countries with developing economy, which took place in January 2015 at Green Templeton College, Oxford (this report is based on conclusions reached at the symposium on Ageing in Emerging Markets organized by the Emerging Markets Symposium (EMS ) at Green Templeton College, Oxford), it was stated that the provision of decent living of elderly people against the background of increasing life expectancy assumes solving the problem of increasing the retirement age, changes in pension plans, reducing the size of welfare payments. In Russia, raising the retirement age is being discussed both in the Government and among the scientific community [6]. In October 2015, a government commission approved a law draft about increasing the retirement age for state employees to 65 years. The pension reform held in 2015 encourages citizens to apply for their pension rights that as late as possible, for example, when having applied for pension rights at the age of 65 rather than 60 , a man will receive a pension by $85 \%$ more [7].

At the same time Russia hosted the III National Conference on Aging "A society for all ages", where in some reports it was suggested that the existing in Russia early retirement was negative for older people themselves, as their employment potential remained unclaimed [8]. Taking into account these facts, the organization of life of elderly people should be considered in the context of creating conditions for the labor activity stimulation of people of retirement age. The presented problem should be studied in the following aspects: 1 . How to interest an elderly person to continue work; 2 . How to interest an employer to save a job for an elderly employee; 3 . What working conditions allow the use of the labor potential of elderly people in the world of high technology; 4. What changes need to be taken in the legislation to regulate the employment of the elderly. In this article subjective factors of the aged work will be considered, i.e. the first two aspects of the problem.

\section{Results and discussion}

In accordance with the above facts, the subject of our research will be the elderly in the first ten years after retirement age, i.e. women aged 55 to 65 and men aged 60 to 70 years old. In our opinion, the interest of people in the first ten years of retirement age to continue to work involves two aspects: objective - the standard of living and subjective - personal reasons for the continuation of human work. According to the State Statistics Committee of the Russian Federation for the 1 st quarter of 2015 , the level of the economically active population among the population of working age is 29.8 $\%$, with a peak labor activity, which accounts for the first 10 years after reaching retirement age. We think that the main reason for interest in the work is the low living standards of pensioners in Russia. The standard of living depends on real income and determines the availability of material and nonmaterial benefits.

The Russia Federation Government Decree of August 28, 2015 has approved a living wage for the second quarter of 2015. The living wage is 10017 rubles, for the working-age population - 10792 rubles, for pensioners - 8210 rubles, for children - 9806 rubles [9]. At the same time the cost of living for pensioners is 8210 rubles, the average size of old-age pensions for the 2 nd quarter of 2015 is 12,826 rubles. [5]. On the basis of the analysis of statistical data, it should be noted that the income of pensioners in Russia exceeds the cost of living. But if we put the problem of a full human life of the elderly, i.e. estimate the ability to enjoy the benefits that are considered to be normal in a given epoch, we will have a different picture. For example, the structure of household consumption expenditure is calculated by the Statistics Committee using the following aggregated parameters: food and non-alcoholic beverages; alcoholic drinks and tobacco products; clothing and footwear; housing services; household goods, home appliances , home care; health; transport; communications; the organization of leisure; education; hotels, cafes and restaurants. If we analyze the pension of an elderly person, focusing on the proposed cost structure, it becomes evident that a significant part of the material and nonmaterial benefits is not available to a person living only on income from pensions. The presented fact has a decisive impact on the labor activity of the elderly, predetermining the need to continue work in the retirement age in order to maintain the quality of life. The subjective component is connected with the relationship of a person to various social factors of life (sense of belonging to society, the existence of family relationships, self-esteem, etc.) and requires further study. 
Saving the elderly employee's workplace by the employer depends on age stereotypes prevailing in society. Research stereotypes existing in society with respect to the elderly are implemented in the context of an independent subject of study [10], [11], [12], in the context of the problems ageism [13], [14], [15] and in the context of social activity of the specified group [16], [17] and [18]. By analyzing the attitude to elderly people in society, it should be noted that the perception of old age is greatly affected by economic and geopolitical factors and traditions that are specific for the society. In this paper we will present a study of stereotypes that affect students of management specialties in Russian institutions of higher education between the ages of 20 to 25 years old. This category was chosen because of the fact that students consider the category of older people not only as a certain social group which is present in the society, but in the context of their professional knowledge and skills. Indeed, the teaching and research activity involves a long professional activity, and people of these professions rarely retire immediately on reaching retirement age [19], [20]. The activities in the professional field requires constant communication with people of different ages, the need for continuing further education, the mastery of modern technology, what is not associated with the image of older people in modern society. In addition, during this period of the person, it is possible to influence some of the components of his / her worldview [21].

The stereotype will be explored in the aspect proposed by American journalist Walter Lippmann in the "Public Opinion" [22]. Lippmann, following Gestalt psychology, suggests that people first creates a picture of the object, and only then perceive it, what greatly simplifies the process complex reality perception and indicates that the formation of patterns are strongly influenced by the media, especially which use visualization as a means of presentation. Also, in our study a modern interpretation of the concept "stereotype" - emotive and resistance to change is taken into account. Stereotypes are rarely realized, they are assimilated by the social contacts in the socialization process of the individual, through personal or indirect (through the media) contact, through life experience. In most cases, patterns are used in the situation of low human cognitive motivation, facilitating the design of social space, thus determining behavioral intention and behavior regarding media stereotypes. This research has attempted to compare the stereotypes about the elderly, formed in young people and the influence of stereotypes on the perception of older employees.

\section{Conclusion}

To determine the understanding of the "elderly man" we asked to choose the age that characterizes this group of people. $12 \%$ of respondents indicated the age of "over 50 years old", $77 \%$ - over 60, $11 \%$ - "over 70 years old". Thus, the students' understanding of old age corresponds to existing theoretical knowledge and statistical practices. Since the study was conducted among students of administrative specialties, who in the process of education obtain the information about the different age classification society, the question was proposed to determine the attitude of students to old age. The main characteristic of the attitude - subjectivity, which presents human values [23], a course of action implemented by the person in a particular situation. To determine the attitude with respect to the elderly group, we asked: "Specify the number of elderly teachers, who work with you in the learning process".

The answers were as follows: $10 \%$ said "from $60 \%$ "50\% - "from 15 to $30 \%$, $40 \%$ - "from 0 to $10 \%$." The correlation of the responses to the previous question and the actual number of teachers of the elderly age leads to the conclusion that the attitudes and the subjective perception of $50 \%$ of students corresponds to the existing knowledge, $40 \%$ have a positive perception of age. Perhaps, a provided favorable situation is explained by the following factors: the traditional image of an elderly man in Russia is associated with the image of "grandma" and " grandpa ", which determines the pattern of behavior according to which the elderly should focus on taking care of their grandchildren. In this context, active working people are not seen as the elderly. Then we asked to formulate from three to five adjectives that are used by students in the process of thinking about old age. When analyzing the words used for old age description, it is necessary to pay attention to a small variety of words used by students as well as the prevalence of negative characteristics.

The latter fact can be partially explained by the use of official and informal languages a small variety of words for the description of the elderly age and the concepts having a negative connotation (age survival, old age, senility, decrepitude, etc.). As a result, five stereotypes and their characteristics have been determined:

A good family man (grandparents): experienced, wise, kind, family oriented;

A good worker: strict, demanding, responsible, hardworking;

Conservatism: retarded, traditional, conservative;

Bad character: boring, passive, slow, grumbling;

Sophisticated lifestyle: illness, loneliness, difficulties and poverty.

On the basis of the stereotypes we have proposed the following assumptions about the attitudes of students to elderly employees: 1 . The stereotype of a "good worker" shows that elderly employees can be trusted with complicated work, they are more reliable in comparison with younger employees; when working in group, elderly employees are a guarantee of the job quality, but in conjunction with the stereotype of "bad character" it can be assumed that the interaction with the staff of the elderly is difficult for colleagues; 2. The stereotype of "conservatism" shows that older workers are not willing to develop new knowledge, they are difficult to teach that in the modern world it is a definite drawback

In order to test the hypothesis, students were asked to answer questions about the characteristics of elderly teachers. Hypothesis 1 was tested with questions about the attitude of older and younger age groups teachers to 
work. The results were as follows: elderly teachers compared with young ones are seen as more responsible and strict. In turn, teachers of younger age compared with older ones are perceived to be more interested in work, much kinder to students. Influence of stereotype "bad character" to work perceptions of older teachers was investigated by determining the views of students on the role of older employees in the labor process. $60 \%$ of students found that older teachers can conduct classes with students and participate in scientific research; $30 \%$ identified that older employees can be involved in the labor process in an advisory capacity with only young teachers; $10 \%$ said that upon reaching retirement age, older teachers should retire.

Hypothesis 2 was tested with the questions about the actuality of the classes by teachers of older and younger age and the use of modern methods and technologies. Students identified the classes of older employees as informative, but focused on the problems that have existed for some years. According to such indicators as "interesting", "informative", "reflection of the latest achievements in the industry," the young teachers have a significant advantage over the older. In characterizing the teachers of different ages on such parameters as "active in the development of topical issues", "seek to develop new methods and technologies", young teachers are far ahead of seniors, confirming thus the second hypothesis.

If average life expectancy increases, the cost of the state associated with the aging of the population will increase. To eliminate the negative financial impact of longevity, it is necessary to solve the problem of increasing the retirement age, increasing contributions to pension funds, reducing the size of payments and social guarantees. Despite the unpopularity of these measures, the governments of different countries will be forced to take them in a short time what actualizes the problem of forming positive stereotypes with respect to employees of retirement age.

The study of stereotypes regarding the elderly conducted among the students of Tomsk universities has revealed 5 stereotypes and their characteristics. An analysis of the words chosen by students to describe the elderly shows little diversity in the attitude of young people to the elderly. Content analysis shows that in the Russian language practically there are no concepts allowing creation of a positive image of the elderly. Creation of the appropriate language and ways of its spread is one of the problems of modern gerontology. Study of the effect of the stereotypes on the perception of older employees by students has showed that there is a positive outlook.

\section{Acknowledgment}

The influence of stereotypes on the perception of the elderly in the context of employment shows that older workers are perceived as people with experience and knowledge, but these experience and knowledge are irrelevant. The stereotype of conservatism forms the attitude to elderly employees as not able to study, to adopt new methods and technologies, what undoubtedly makes them less important for the employer and less competitive compared to younger employees. In our opinion, it is necessary to form in students a positive attitude towards the ability of the elderly to learn and their desire to work in team, as part of the students in the future will take a decision on keeping older employees in the staff and the principles of organization of work with this group of employees. Teachers of the elderly age should play an essential role in this process as for students this is the first experience of a conscious evaluation of the skills of all employees including the elderly. In addition, it is possible to introduce in the educational process the courses in which management methods and approaches to the work organization of different categories of employees will be explained. This has been done in Tomsk Polytechnic University; the analysis of this innovation will be presented in further papers.

\section{References}

1. Ageing in emerging markets. The emerging markets symposium. - Green Templeton college Oxford, 7 (2015)

2. Drucker P. Management, Challenges for the $21^{\text {st }}$ Century, 207 (1999)

3. National Strategy of Action for the elderly till 2015 // URL http://regulation.gov.ru. Federal portal draft regulations (the date of access: 10/14/2015)

4. International Monetary Fund - URL https://www.imf.org/external/index.htm (the date of access: 01/02/2015)

5. The Federal State Statistics Service of Russia - URL http://www.gks.ru/wps/wcm/connect/rosstat_main/r osstat/ru/statistics/population/demography/\# (the date of access: 09/19/2015 )

6. TASS. Russian news agency. - URL http://tass.ru/obschestvo/2369152

7. Pension Fund. Official site. - URL http://www.pfrf.ru/

8. The official website of the conference "Society of all ages". - URL http://www.ageing forum.org/ru/event/conference-2015/programma/

9. Resolution of the Government of the Russian Federation from 28.08.2015 - URL http://publication.pravo.gov.ru/Document/View/000 1201509010019. Official Internet portal of legal information (the date of access 09/20/2015)

10. B.E. Blaine, Understanding the psychology. (Printed in the United States of America, 2013 by SAGE Publications, INS)

11. A.V. Pisarev, Soc. Res., 4, 51 (2004)

12. D.M. Rogozin, The social situation of the elderly in the Ivanovo region. The report on the first stage of a complex sociological research (2012)

13. R. Butler, J. of Soc. Is. 36 (2) (1980)

14. J.A. Wilkinson, K.F. Ferraro Thirty years of ageismus research. In T.D. Nelson (Ed.) Ageism: Stereotyping and prejudice against older adults (2002) 
15. J.A. Wim van den Heuvel, M. Marc van Santvoort, Eur. J. of Ag.. 8(4), 291-299 (2011)

16. A.A. Smolkin, Soc. Res. 54(3), 177-188 (2014)

17. M. Myck, In Eur. J. of Ag., 12(1), 3-5 (2015)

18. P. Tychkin, Proc. Soc. and Beh. Sc., 166 (2015).

19. I.B. Ardashkin, N.V. Martyushev, V.P. Bezborodov, Proc. - Soc. and Beh. Sc, 166, 227-231 (2015)

20. A.Y. Chmykhalo, Proc. - Soc. and Beh. Sc, 166, 480-487 (2015)

21. M. A. Makienko, A. N. Panamareva, Proc. - Soc. and Beh. Sc, 166, 415-421 (2015)

22. U. Liipman Public opinion (M., Institute of Fund "Public opinion", 2004)

23. S. Oskamp, P.W. Schultz Attitudes and opinions, (N. J.: Lawrence Erlbaum Associates, 2005) 